\title{
CARACTERIZAÇÃO DAS CONTENÇÕES UTILIZADAS NAS ENCOSTAS DA BA- 099, ENTRE CONDE E SUBAÚMA
}

\author{
Jornis Vilas Boas Santos; Carlos César Uchôa de Lima; Ailana da Silva Mendes ${ }^{3}$ e Túlio \\ Schitini Alves de Oliveira ${ }^{4}$
}

1. Bolsista PIBIC/FAPESB, Graduando em Engenharia Civil, Universidade Estadual de Feira de Santana, e-mail:

\author{
jorn_is@hotmail.com
}

2. Orientador, Departamento de Exatas, Universidade Estadual de Feira de Santana, e-mail: uchoamaster@gmail.com

3. Participante do projeto, Departamento de Tecnologia, Universidade Estadual de Feira de Santana, e-mail: ailanamendes@hotmail.com

4. Participante do projeto, Departamento de Tecnologia, Universidade Estadual de Feira de Santana, e-mail: tulioschitini@hotmail.com

PALAVRAS-CHAVE: Neotectônica; Contenção de Encostas; Movimento de Massa.

\section{INTRODUÇÃO}

Movimentos de massa ou movimentos coletivos de sedimentos, solos e rochas, tem sido objeto de estudo nas mais diversas regiões, já que os mesmos, além de serem agentes da evolução da paisagem, trazem também, implicações para cidades topograficamente acidentadas e para as margens de diversas rodovias. Uma das causas mais comuns no desencadeamento de movimento de massas seria a modificação geométrica da massa terrosa ou rochosa (Guidicine e Nible, 1984) com a implantação de taludes, que margeiam ruas e estradas. Massad (2003) afirma que as causas desses movimentos de massa são, antes de tudo, ditas "naturais", pois há uma tendência na natureza à peneplanização, ou seja, os solos das encostas tendem a descer para atingir um nível de base.

Compreende-se talude como quaisquer superfícies inclinadas que limitam um maciço de terra, de rocha ou de terra e rocha, podendo ser naturais como as encostas e artificiais que são os taludes de cortes e aterros respectivamente, encontrados ao longo de rodovias, por exemplo (CAPUTO, 1987).

Para que se estabeleça o risco de movimento de massa em uma encosta, é determinado um coeficiente de segurança. Segundo Massad (2003) na natureza os coeficientes de segurança estão em torno de 1 (um) para ações críticas, isto é, chuvas intensas e prolongadas, infiltração da água e saturação do solo, ou seja, quando o homem pretende modificar a inclinação do terreno, esta ação deve ser planejada, a fim de minimizar a alteração da geometria da encosta. Assim, após o corte ou escavação devem-se tomar algumas medidas de proteção para evitar a erosão. Os cortes feitos nas estradas podem atingir zonas de fraqueza que podem estar ligadas à constituição do material rochoso e ou sedimentar, ou oriundo da ação de tectonismo como, juntas e falhas (COELHO \& LIMA 2006, DANTAS \& LIMA 2008, LIMA et al 2008, LIMA, 2010). Para que os cortes de estrada possam manter a estabilidade esperada e não provocar acidentes, é necessário a execução de obras de contenção, que devem ser escolhidas, de acordo com a dimensão, os materiais constituintes e as zonas de fragilidades da encosta. A utilização dessas contenções requer manutenções periódicas, a fim de que elas atuem de forma correta, tornando a encosta segura.

Esta pesquisa foi realizada entre as cidades de Conde e Subaúma e tem como objetivo, caracterizar os diversos tipos de contenção de encostas ao longo da rodovia BA-099, observando a adequabilidade das mesmas, levando-se em conta os parâmetros físicos observados. 


\section{MATERIAL E MÉTODOS}

Com o intuito de alcançar o objetivo deste trabalho, fez-se necessário estabelecer alguns procedimentos metodológicos.

1- Durante todo o período foram feitos levantamentos bibliográficos em livros e artigos que abordassem a área da Geotecnia;

2- Estudos de campo foram feitos com a finalidade de identificar, caracterizar e descrever os diversos tipos de contenções utilizadas. Para esta etapa foi necessária a utilização de alguns instrumentos tais como bússola, GPS, câmera fotográfica e trena. A bússola foi utilizada para analisar os planos de fraqueza e o ângulo de inclinação das encostas. As coordenadas UTM foram obtidas através do GPS e os recuos e a largura dos taludes foram mensurados através da trena. Para o registro dos tipos de contenção observados nos taludes, foi utilizada a câmera fotográfica.

Foram estudados e registrados em fotografia 16 (dezesseis) encostas, sendo que 2 (duas) delas foram escolhidas para serem analisadas e descritas em detalhe, levando-se em consideração os tipos de contenção utilizados e os níveis de alteração e/ou preservação dos taludes.

\section{RESULTADOS E DISCUSSÃO}

Ao longo das encostas estudadas, na rodovia BA-099, foi observada em sua maioria uma modificação do modelo inicial de contenção. Tal mudança foi necessária para atender as eventuais alterações ocorridas nas encostas devido aos movimentos de massas e erosão do solo, buscando assim, satisfazer as novas necessidades de estabilização.

Na primeira encosta (Figura 1) com coordenadas UTM 24L 0655010; 8703541 são encontradas contenções que necessitam de manutenção. As contenções observadas no talude fora as bermas, sacos de solo-cimento (posteriormente jateados com concreto) e drenos que estão totalmente entupidos, o que impede o escoamento da água, podendo causar um acúmulo de água no terreno. Ainda nesse ponto, observou-se a base da encosta ocupada por fragmentos, resultantes de desmoronamentos recentes, o que implica em falta de manutenção. Segundo Massad (2003) a utilização de drenos profundos, tem o intuito de abaixar o nível freático, reduzindo assim, as pressões neutras e, consequentemente, aumentar a estabilidade do talude. Também foi utilizado canaletas em degraus, que funciona como um sistema de drenagem superficial, além, de minimizar a velocidade da água com a utilização de degraus, esta apresenta um bom estado de conservação.

Nessa encosta um dos principais problemas observados, foi a falta de manutenção nos drenos de escoamento. No entanto, este talude não demonstra riscos para a rodovia, pois há presença de grandes quantidades de óxido de ferro, que cimenta os sedimentos e dificulta $o$ processo de erosão e movimentos de massa. 


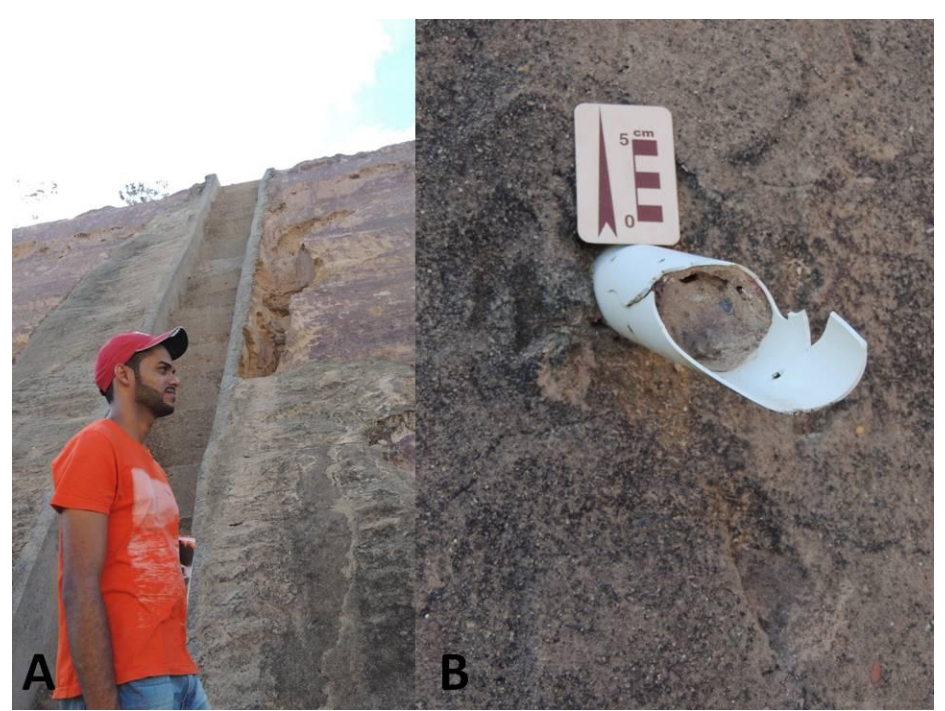

Figura 1: A- Canaletas do tipo escada em degraus atuando, como dispersor de velocidade das águas pluviais; B- Drenos totalmente entupidos, impedindo o escoamento das águas pluviais que infiltra no terreno. Fonte: O autor (2015).

A Segunda encosta demonstrada na Figura 2 possui coordenadas UTM 24L 0635039; 8664415. São visíveis as várias tentativas de mudança do percurso das canaletas, sendo que essas mudanças foram feitas no intuito de barrar a expansão de uma grande voçoroca, que se encontra em estado avançado. A fim de diminuir a velocidade das águas pluviais é necessária a modificação do tipo de canaleta acrescentando degraus, pois esta encosta já passou por inúmeras mudanças e mesmo assim, continuam a causar a erosão do talude. Uma grande quantidade de óxido de ferro é visível na encosta, e este atua como agente cimentante, dificultando o processo erosivo e eventuais movimentos de massa. Ainda assim, o grande desnível topográfico, associado a alta inclinação da encosta, tem feito com que os processos erosivos estejam atuando intensamente.

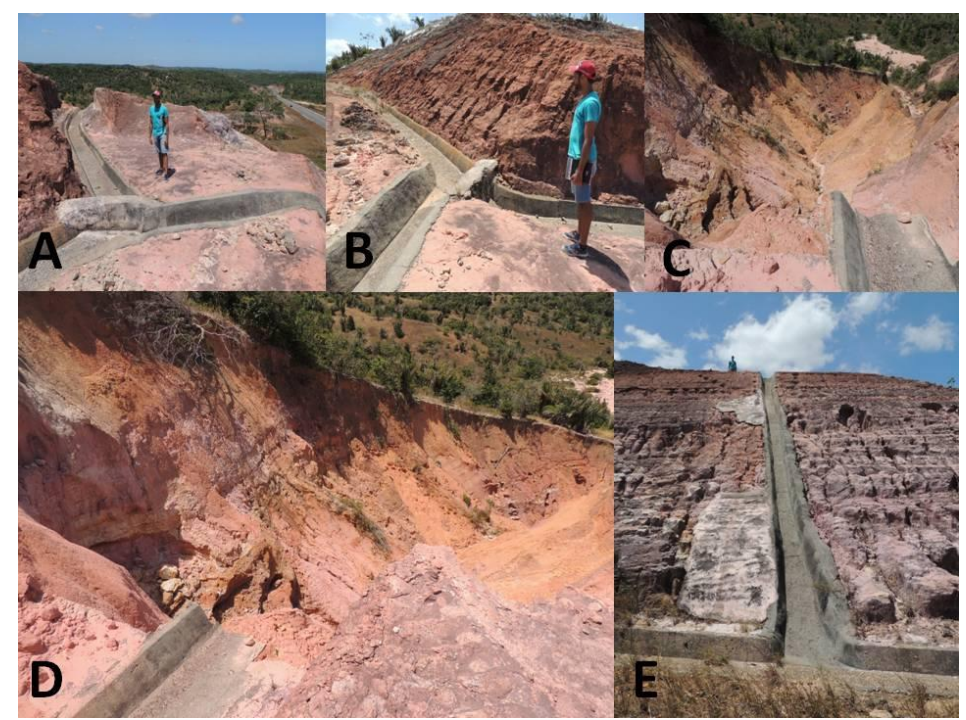

Figura 2: A e B- Alteração nos percursos das canaletas; C e D- Talude alterado devido a formação de uma grande voçoroca; E- Canaleta necessitando de alteração em seu formato, acrescentando degraus. Fonte: O autor (2015). 


\section{CONSIDERAÇÕES FINAIS}

Os resultados encontrados nesta pesquisa evidenciam um grande poder erosivo, já que a área estudada encontra-se em uma região de alta pluviometria e as contenções, em muitas encostas, não possuem manutenção adequada. Desse modo, é necessário que, além de contenções adequadas, haja também, manutenções periódicas, com o intuito de manter a estabilidade das encostas.

$\mathrm{Na}$ maioria dos afloramentos, foi possível perceber que o processo erosivo e os movimentos de massa foram desencadeados por falta manutenção ou até a inadequação de algumas contenções, como a falta de canaletas que drenem superficialmente as encostas. A ausência dessas contenções gera preocupações com as juntas neotectônicas, que serve de conduto para o escoamento da água da chuva, gerando o processo de ravinamento (LIMA 2010). No decorrer do tempo, essas ravinas aumentam a sua dimensão tornando-se voçorocas, podendo destruir qualquer estrutura de contenção presente.

Em algumas encostas foi possível observar que em sua maioria, as que não apresentaram contenções possuíam em sua composição grandes quantidades de agentes cimentantes, como o óxido de ferro. A presença de agentes cimentantes em uma encosta não garante que a mesma vá permanecer estável, ainda mais, em encostas de escavação que possui toda sua geometria alterada. Por isso, a construção e a manutenção adequada de contenções são essenciais para assegurar que a encosta não apresente risco de erosão e eventuais movimentos de massa.

\section{REFERÊNCIAS}

CAPUTO, Homero Pinto, Mecânica dos Solos e suas Aplicações. 6. ed. Rio de Janeiro: LTC, 1987

COELHO, M.G.A. \& LIMA, C.C.U. Análise tectônica preliminar do Grupo Barreiras no litoral norte do Estado de Sergipe. In: Simpósio Nacional de Geomorfologia, 6, Goiânia 7p. 2006.

GUIDICINI, G.; NIEBLE, C. M. Estabilidade de Taludes Naturais e de Escavação. Edgar Blücher. São Paulo, 1984.

LIMA, C. C. U. Evidências da Ação Tectônica nos Sedimentos da Formação Barreiras Presentes no Litoral de Sergipe e ao norte da Bahia. Revista de Geografia. Recife: UFPE DCG/NAPA, v. especial VIII SINAGEO, n. 1, Set. 2010.

LIMA, C.C.U.; DANTAS, J.J.R.;COELHO, M.G.A. Fragilidades Tectônicas nas Encostas das Rodovias Litorâneas de Sergipe e Extremo Norte da Bahia. In: CONGRESSO BRASILEIRO DE GEOLOGIA DE ENGENHARIA, Porto de Galinhas- PE, 2008. MASSAD, FAIÇAL. Obras de Terra: Curso Básico de Geotecnia. 1.ed. São Paulo: Oficinas de Textos, 2003. 